Association for Information Systems

AIS Electronic Library (AISeL)

ICEB 2009 Proceedings

International Conference on Electronic Business

(ICEB)

Winter 12-4-2009

Examining The Role of Information Technology in Cultivating

Firms' Dynamic Marketing Capabilities

Eric T.G Wang

Han-fen Hu

Paul J.H Hu

Follow this and additional works at: https://aisel.aisnet.org/iceb2009

This material is brought to you by the International Conference on Electronic Business (ICEB) at AIS Electronic Library (AISeL). It has been accepted for inclusion in ICEB 2009 Proceedings by an authorized administrator of AIS Electronic Library (AISeL). For more information, please contact elibrary@aisnet.org. 


\title{
EXAMINING THE ROLE OF INFORMATION TECHNOLOGY IN CULTIVATING FIRMS' DYNAMIC MARKETING CAPABILITIES
}

\author{
Eric T. G. Wang ${ }^{1}$, Han-Fen $\mathrm{Hu}^{2}$, Paul Jen-Hwa $\mathrm{Hu}^{3}$ \\ ${ }^{1}$ Department of Information Management \\ School of Management, National Central University, Taiwan \\ ${ }^{2,3}$ Department of Operations and Information Systems \\ David Eccles School of Business, University of Utah, USA \\ 1ewang@mgt.ncu.edu.tw; ${ }^{2}$ han-fen.hu@business.utah.edu; ${ }^{3}$ actph@business.utah.edu
}

\begin{abstract}
Dynamic capabilities enable firms to reconfigure limited resources or relative strengths to respond to rapid changes in market conditions. This study considers the central role of IT in creating and enhancing dynamic capabilities by analyzing the essential determinants of dynamic marketing capabilities and proposing a model that includes market orientation, IT infrastructure capabilities, and use of IT to support CRM. Tests using a large-scale survey support the model and most of its hypotheses. The results reveal significant effects of a firm's market orientation and use of IT to support CRM and the functionality of IT infrastructure capabilities on dynamic marketing capabilities.
\end{abstract}

Keywords: Dynamic Marketing Capabilities, Dynamic Capabilities, Market Orientation, IT Support for CRM, IT Infrastructure

\section{Introduction}

Competitive advantages are critical to firms and continue to receive substantial attention from researchers and business managers. The research topics in the competitive advantage area evolve overtime in response to the technology and environment changes. For example, researchers have adopted the perspective of dynamic capabilities to examine competitive advantages in recent decades to capture the dynamism in rapid, unpredictable changing environments. Dynamic capabilities, defined as firms' abilities to reconfigure their finite resources and respond to market changes effectively [1] [2], is needed for firms to adapt to the changing business environment [3]. In addition, the role of information technology (IT) is also recognized as a central enabler in the competitive advantage literature [4]. IT is essential for firms that strive for sustainable competitive advantages through process improvement, operational excellence, and customer intimacy [5]. However, there is a miss link between IT and dynamic capabilities. Prior research has not focused on how IT infrastructure can enable better IT support for business process and thus generate dynamic capabilities in corresponding areas of the firm. Although IT represents a vital strategic asset in business, its effects on the firm's dynamic capabilities are not well understood.

The concept of dynamic capability is broad and relates to various business processes and activities [3] [6]. Although the extant literature offers some interesting strategic insights, few studies have examined the dynamic capability of a specific and crucial area of the firm. Of particular importance is the role of IT in supporting key business processes or activities. This research void requires more detailed conceptual analysis and empirical testing of the role of IT in creating and cultivating firms' dynamic capabilities in crucial aspects of their business. In addition, IT resources have been conceptualized in a variety of fashions in the literature. In order to better capture the contributions of IT to business values, we argue that the overall IT infrastructure capabilities and IT support to a specific business application should be both included in the study.

Among the various aspects of business, marketing is considered a critical area in developing firms' dynamic capabilities. In the ever evolving market conditions, dynamic marketing capabilities allow firms to identify essential market signals, evaluate existing and future processes and services, and design and execute effective responses to market changes [3]. Dynamic marketing capabilities can directly influence product development, service design, and long-term customer relationships, which jointly affect the firm's revenues and competitiveness [7]. However, most prior studies tend to approach dynamic capabilities generally [8] [9] [10] and thus offer few analyses or discussions of dynamic capabilities of the marketing function. To address this backdrop, we investigate firms' dynamic marketing capabilities together with the emphasis on the important practices in the marketing function. In particular, customer relationship management (CRM) is the "marketing mantra of today" [11], and the CRM efforts involve a huge amount of information processing 
and needs IT support to facilitate such efforts.

We analyze key determinants of dynamic marketing capabilities with an emphasis on the central role of IT in creating and augmenting these capabilities. We propose a model that relates a firm's dynamic marketing capabilities and its market orientation, IT infrastructure capabilities, and use of IT to support CRM. We test this model and the associated hypotheses using the data collected from a large-scale survey of major Taiwanese manufacturers and service firms. According to our results, a firms' market orientation, functionality of its IT infrastructure capabilities, and use of IT for supporting CRM have significant influences on the firm's dynamic marketing capabilities.

By examining the central role of IT in creating and enhancing dynamic marketing capabilities, our study contribute to the IS literature by addressing how different types of IT resources can used to promote business values. We also contributes to competitive advantage literature by exploring firms' dynamic capabilities from a fine-grained marketing perspective, anchored by the central role of IT in supporting key marketing processes and activities. Furthermore, we generate empirical evidence suggesting the direct or indirect effects of these key determinants on a firm's dynamic marketing capabilities.

\section{Literature Review}

In the area of competitive advantages analysis, the resource-based view (RBV) has been used as a theoretical lens in prior information systems (IS) research to explore the contribution of IT to firm performance [12]. The RBV provides a logical framework for examining how firms gain sustainable competitive advantages [13], with a focus on firms' finite resource capabilities. It also assumes that these resources are distributed heterogeneously across firms and that the differences in resource capabilities among firms remain relatively stable over time. These assumptions make the RBV limited in highly volatile environments, because it cannot explain how firms acquire and develop resource capabilities and make them sustainable over time [1]. Some researchers therefore shift their perspective to dynamic capabilities [1] [2] [14], which refer to a firm's ability to obtain competitive advantages through its resources that enable effective responses to changes in the business environment [1] [2]. Dynamic capabilities underscore the importance of the "history" of current capabilities, as well as the importance of expanding current capabilities in the future for sustainable competitive advantages [15].
For example, in an industry characterized by the continual availability of innovative or even disruptive technology, a firm's success or failure greatly depend on effective technology deployments and assimilation with business [16]. Dynamic capabilities further enable a firm to orchestrate its operational capabilities and resources, beyond routine production and service delivery; hence, they have significant influences on the firm's performance and can determine its competitiveness in the market. A firm's dynamic capabilities are difficult to replicate [2] [16], even if competitors can observe or infer their coherence or rationality from the firm's behaviors or performance.

Dynamic capabilities are multifaceted and prevail in many crucial aspects of business. Of particular importance is marketing; firms that possess desirable dynamic marketing capabilities can adjust their marketing processes and activities in an effective and timely manner to better serve and retain their customers, increase sales, and cultivate favorable long-term customer intimacy. In this study, we define dynamic marketing capabilities as a set of specific and identifiable processes that the firm exhibits to indicate its ability to exploit its finite resources- by integrating, reconfiguring, gaining, or releasing these resources - and respond to important market changes [1]. These capabilities include a firm's product/service development [1] [17] [18], pricing [7], channel design (i.e., place) [18], and promotion [15], which are manifested in the effectiveness of its marketing mix. Previous research explores some issues peripheral to dynamic marketing capabilities.

A review of the extant literature also suggests the importance of market orientation [2] [8] [19] [20] [21], IT infrastructure capabilities [22] [23], and IT support for CRM [5] [24], each of which can affect a firm's dynamic marketing capabilities significantly. Firms embracing a highly market-oriented culture likely will emphasize comprehensive data gathering, seamless data integration, thorough analyses, and agile market intelligence generation, which are critical for steering and coordinating their CRM processes and activities and ultimately expanding their dynamic marketing capabilities. This strategic, customer-centric, data-driven CRM focus requires the effective use of IT, though little research explains how firms may create or enhance their dynamic marketing capabilities through the use of IT.

Market Orientation: Research on market orientation addresses how organizations adapt to their environments and develop competitive advantage [25]. Market orientation generally 
refers to the organization-wide generation of market intelligence pertaining to current and future customer needs and the dissemination of such intelligence across functional departments and business units to ensure effective, timely responses to key market changes [19] [21] [26]. The extent to which a firm is market oriented dictates the emphasis it places on market information and internal coordination with respect to long-term firm performance and profitability; highly market-oriented firms constantly strive for value creation for their customers and performance improvements [27]. Firms with a high market orientation also demand constant monitoring of market conditions, frequent market trend analyses, and thorough understanding of customers' needs and competitors' strategies. Previous research empirically examines the impacts of market orientation on firm profits [8] [9] [10] and employees' morale, job satisfaction, and commitment or loyalty [9]. The relationship among market orientation, a learning organization [10] [25], and innovation [25] also has been studied in prior research.

IT Infrastructure Capabilities: As a central enabler, a firm's IT infrastructure forms the backbone of its IT architecture and applications; it is indispensable for effective business processes or functions [28]. Salient definitions of IT infrastructure seem to embrace both static technical resources (shared technological components such as hardware platforms, network equipment, telecommunications technology, data, and system applications) and the shared IT services that underpin the systems for supporting the firm's processes, business operations, or decision making [29]. An IT infrastructure differs from the transaction processing or management information systems (or associated applications) that it supports, in that it establishes a fundamental basis for current and future business systems and applications but is not specific to any business process or management function. It also provides the flexibility necessary for coping with uncertainty in future needs [22]. According to [30], a firm's IT infrastructure capabilities can fundamentally influence the extent to which it can create, share, and use data, information, and knowledge in an effective and timely fashion.

In general, an IT infrastructure consists of network and telecommunications technology and platform technology such as hardware and operating systems [30]. These two types of technology can be distinguished as connectivity and functionality, respectively [22]. Connectivity refers to the ability of an IT infrastructure (or its components) to link to other components within and beyond the organization's boundaries [30]
[31]; it determines the firm's underlying capacity for providing data, voice, and video across locations that span large distances [28]. Functionality entails an array of various enterprise-wide fundamental applications or services [23]; it provides a kernel and flexible base for the firm's long-term strategic intent. In general, the functionality of an IT infrastructure is relatively more stable than the business operations or applications it supports [30], hereby creating an enterprise-wide platform for various information systems and business applications. Functionality further affects a firm's ability to add, modify, and remove the modules of business applications, with few adverse ripple effects on existing applications [22] [30] [31]. As a whole, a firm's IT infrastructure capabilities can be gauged in terms of connectivity and functionality [22] [29]. Firms have relatively greater IT infrastructure capabilities when they can support a wide range of fundamental applications or services, across various geographic locations or work groups. These capabilities represent crucial resources for firms and can uniquely fuse the technology and human infrastructure [22] [23].

IT Support for CRM: Firms constantly seek technological opportunities to solve their business problems or respond to market changes better and faster [32]. Effective CRM allows firms to identify valuable customers, obtain and accumulate crucial knowledge about them, and thus create greater value for them [33]. Prior research seems to focus on examining CRM effects on customer satisfaction and, firm performance [34] and customer loyalty and firm profitability [24] [35]. By and large, IT support for CRM denotes the degree to which a firm uses IT to support and improve its CRM activities. Adequate use of IT can increase the effectiveness and efficiency of CRM. By collecting and analyzing detailed customer demographic and behavioral data, firms can improve their communications with customers, enhance marketing strategies and activities, select appropriate distribution channels, and make customer support and call centers effective [5]. Inherently CRM is information intensive; thus, its effectiveness relies on the firm's ability to gather and integrate voluminous, comprehensive data about customers and their behaviors, perform detailed processing and analyses of these data, and propagate the resulting information and knowledge quickly throughout the organization. Moreover, IT can empower firms to perform these tasks better [35]. For example, a firm can use database marketing, decision support systems, or analytics software to improve its customer communications or service channels. Using IT, firms can improve their customer intimacy, stay 
abreast of market changes, anticipate market trends, cut costs, increase sales and revenues, and/or foster customer satisfaction and loyalty, thus creating sustainable competitive advantages [5]. These effects suggest the important role of IT support for CRM in terms of determining the firm’s dynamic marketing capabilities.

\section{Research Model and Hypotheses}

We propose a factor model that explains a firm's dynamic marketing capabilities using market orientation, IT infrastructure capabilities, and IT support for CRM (see Figure 1). We distinguish the connectivity and functionality of the firm's IT infrastructure capabilities because they serve distinct purposes and have logical delineations. In particular, our model emphasizes the central role of IT in creating and enhancing firms' dynamic marketing capabilities through its support for CRM, as well as the infrastructural capabilities.

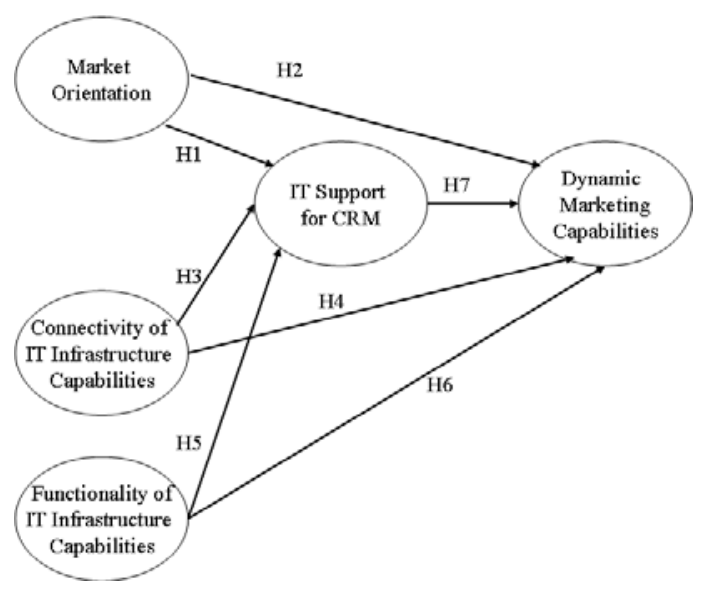

Figure 1: Research Model

A firm's market orientation can be described by information acquisition, dissemination, and responsiveness [19] [27]. Highly market-oriented firms tend to pay closer attention to customers-the locus of CRM [32] [34]. To achieve their business objectives in a competitive environment, these firms must be effective in CRM and often demand substantial IT capabilities for collecting, integrating, and analyzing vast amounts of customer data generated by various channels or stored in multiple sources. For example, a highly market-oriented firm might use technology to support its operational CRM (e.g., personal exchanges, face-to-face dialogue, phone-based inquiries or service requests, customer complaint management), from which it gathers essential data about customers and their product preferences or assessments. To understand their customers and their needs or preferences, firms might use IT to enhance their analytical
CRM for demographic analyses, market segmentation, customer profiling, purchase behavior analysis, marketing decision support, or promotion design. In addition, a firm could use IT to improve its collaborative CRM through call center automation and seamless integrations of various contact points to reach customers. Prior research highlights the importance of IT for CRM [26] and shows that firms with a relatively higher market orientation are more likely to explore, experiment, and utilize technological solutions to address their challenges in CRM [32] than are firms that are low in market orientation.

H1: A firm's market orientation is positively associated with its use of IT to support CRM.

Highly market-oriented firms also have a greater need for market intelligence than their counterparts that are low in market orientation [9], implying a positive influence of market orientation on dynamic marketing capabilities. To stay highly market oriented, firms must understand the changing market conditions and stay atop of emerging trends, which requires them to scan key market events constantly to detect alarming changes, as well as generate and execute effective responses in an agile and timely fashion. These firms often exhibit a paramount need for dynamic marketing capabilities to adjust their marketing processes and activities by reconfiguring their resources. Market orientation further demands that firms undertake continual market surveillance [36] and integrate multiple functional departments and channel partners to reconfigure ineffective competencies that will generate promising skills that align better with key market changes [1] [2] [14] [17]. Market orientation has important influences on firm performance measured by new product (service) development effectiveness and cycle time [8] [10] or product (service) market performance [17], which are manifestations of the firm's dynamic marketing capabilities. Accumulated empirical evidence suggests that a firm's market orientation positively affects its dynamic marketing capabilities, as manifested by product development, pricing, or channel design.

H2: A firm's market orientation is positively associated with its dynamic marketing capabilities.

Connectivity offers a central conduit through which different applications can run simultaneously across locations, people, groups, or departments. Such connectivity often appears at different levels, ranging from simple data exchanges within a single business unit to complex application process (typically involving multiple functional departments or external partners) for users that are geographically dispersed [22]. High connectivity also creates the 
basis necessary for sharing and combining distributed, heterogeneous data about customers, such as their demographics, inquiries, behaviors, or transactions. The connectivity of an IT infrastructure establishes an enterprise-wide network for connecting various information systems and computer-based applications related to CRM. Because CRM usually involves multiple departments, business units, and partners and spans channels devoted to customer-centric communications and services [5], the connectivity of an IT infrastructure should influence the firm's CRM practices [33]. Firms with greater connectivity capabilities in their IT infrastructure are better wired and can stay closer to customers and partners through effective data gathering, transmissions, and sharing, all of which are fundamental to the use of IT for CRM support.

H3: The connectivity of a firm's IT infrastructure capabilities is positively associated with its use of IT to support CRM.

The connectivity also represents a services-delivery base for the firm [31]. The connectivity of an IT infrastructure is crucial to the firm's enterprise-wide technology platform, through which various information systems and business applications can be connected [30]. Through network communications and data transmissions, connectivity enables firms to increase their information velocity to achieve cycle time compression and agile market responses [22]. Furthermore, connectivity links a firm and its customers, suppliers, and business partners. Through these vital network connections, marketing processes and activities can be conducted, and important data about customers and their experiences may be gathered, transmitted, and disseminated throughout the firm. With an IT infrastructure that offers greater connectivity, firms can enhance their ability to analyze, evaluate, select, and execute adjustments that involve multiple departments or external partners. The firm's dynamic marketing capabilities then should increase, as manifested in the form of successful process reengineering, agile product development, and effective promotion designs. Previous research shows that firms with a greater connectivity in their IT infrastructure capabilities can engage more effectively in product (service) innovation and continuous improvement, which indicate enhanced dynamic marketing capabilities [30]. Thus, connectivity also is crucial to the firm's dynamic marketing capabilities [28].

H4: The connectivity of a firm's IT infrastructure capabilities is positively associated with its dynamic marketing capabilities.

The functionality of a firm's IT infrastructure capabilities relates closely to the modular component design in IT. Functionality offers the basic services instrumental to a wide array of information systems and business applications [22]. Firms can better design and execute CRM if their IT infrastructure has a higher level of functionality. As a firm's CRM practices evolve over time, its functional IT infrastructure can enhance the CRM system by implementing new applications or changing existing applications to meet new requirements. In addition, greater functionality in the IT infrastructure capabilities offers a more comprehensive and desirable set of fundamental services that support various IS or business applications. Functionality such as adequate database capability, data analysis capability, computational processing in hardware, operating systems, or kernel system software is indispensable to the success of IT-supported CRM. For example, analytical CRM applications depend on the ability to capture customer transactions and extract important patterns from prior product search and purchase data stored in various databases. In this case, a CRM system relies on the IT infrastructure's functionality to support its processing and analyses. When a firm's IT infrastructure offers a greater functionality, it can benefit more from data integrations from different sources, thorough data processing and sophisticated analyses, and novel business intelligence about customers, markets, or competitors. Firms can become more effective in addressing evolving customer needs and market demands by establishing adequate functionality in their IT infrastructure [6], which then better supports the CRM processes or activities.

H5: The functionality of a firm's IT infrastructure capabilities is positively associated with its use of IT to support CRM.

Firms also depend on their IT infrastructure's functionality to respond to essential market changes [38]. In general, this functionality refers to the ability to modify, add, or remove new applications efficiently on the basis of different business application requirements [31]; Infrastructures provide a flexible base for future business initiatives [31]. At a higher level, functionality can enable or support a more comprehensive range of kernel services that collectively provide the foundation necessary for adjusting operations, changing processes, and reconfiguring marketing resources, both internal and external [37]. As a result, greater functionality can enable firms to create initiatives or pursue business opportunities in response to important market changes. Furthermore, functionality can improve data processing and information flows in the organization, through which firms improve their business analyses and decision making. For 
example, firms might leverage the functionality of their IT to analyze information and extract essential business intelligence that will support their strategic decision making or operational efficiency improvement. Through improved application developments and standardized service management, firms can better allocate system resources, closely monitor and fine-tune business operations, and execute process reengineering efforts efficiently. In turn, these efforts can foster the creation and augmentation of their dynamic marketing capabilities for adapting to essential market changes or seizing valuable business opportunities.

H6: The functionality of a firm's IT infrastructure capabilities is positively associated with its dynamic marketing capabilities.

Finally, by using IT to support their CRM, firms can optimize their sales processes, improve customer service designs, combine related and often disintegrated data about customers and the market, enhance service quality, facilitate customer communication, profile valuable customers, and support effective marketing campaigns [5]. With these capabilities, firms become more effective in adapting to market changes, forecasting market demands, or providing customization [5]. For example, firms might discover profitable cross-selling opportunities, increase customer retention rates, foster online exchanges, or refine promotion activities by using analytical CRM technology. Firms also can improve their collaborative CRM by integrating various distribution channels, direct sales storefronts, Web sites, and customer support centers; then, through these integrated channels, they can develop essential data about customers and their behaviors.

H7: A firm's use of IT to support CRM is positively associated with its dynamic marketing capabilities.

\section{Study Design and Data Collection}

Our survey targets leading manufacturers and service firms in Taiwan. ${ }^{1}$ We employed a key informant approach and sent survey packets to the (chief) marketing officer of each firm, who generally has a good understanding of the firm's business and operations from a marketing perspective. Our survey packet consisted of a cover letter that describes our study and its purpose, the questionnaire, and a self-addressed stamped return envelope. To encourage voluntary

\footnotetext{
${ }^{1}$ We target the top 1,000 manufacturers and top 500 service firms listed in the Largest Corporations in Taiwan, published in a special issue by Common Wealth (May 2002).
}

participation, we promised firms, in the cover letter, that we would make, on each respondent's behalf, a donation of $50 \mathrm{New}$ Taiwan dollars (i.e., approximately US\$1.5) to a nonprofit charity organization. We used multiple question items to measure each construct. Specifically, we operationalized market orientation with nine items adapted from MARKOR [20] $]^{2}$, using a five-point Likert scale anchored by "strongly disagreed" and "strongly agreed." These items target market intelligence generation, information dissemination, and firm responsiveness. To measure IT infrastructure capabilities, we used a previously developed and validated scale [22], which includes both connectivity and functionality. Connectivity uses five discrete levels: do not have, send messages, access to information, perform simple transactions, and perform complex transactions. The functionality measure has 13 dichotomous items, for which 1 represents "affirmative" and 0 otherwise. We obtained six items to measure IT support for CRM, according to a previous analysis of the CRM process [33]. These items employed a five-point Likert scale, with 1 being "strongly disagreed" and 5 "strongly agreed." We followed existing discussions [1] and extended the dynamic capabilities analysis [2], with a emphasis on key aspects manifested in the firm's marketing mix: product (service) development, pricing, channel design (i.e., place), and promotion. In particular, we measured dynamic marketing capabilities with 12 question items, using a five-point Likert scale anchored by "strongly disagreed" and "strongly agreed.",

The questionnaire was administered in Chinese, the official language in Taiwan. Adapted items were translated into Chinese by experienced translators, and then two researchers fluent in both English and Chinese reviewed the translation to ensure consistent semantics of the question items between languages. After resolving some minor wording discrepancies, we conducted a pretest to assess the reliability and validity of the instrument. The results are satisfactory; several minor wording changes make the question items more appropriate to the targeted context and subjects.

We sent the survey packets, by postal mail, to a sample of 500 firms randomly selected from our target pool. Each firm had three weeks to complete and return the survey, and at the end of this initial response window, we sent a reminder letter to those from whom we had not received completed surveys, promising them an additional two weeks to do so.

\footnotetext{
2 We adopted the nine widely validated items from the original MARKOR 20-item scale.

${ }^{3}$ Question items are available upon request.
} 


\section{Analyses and Results}

Of the 149 surveys we received, 14 incomplete questionnaires are excluded from our subsequent analyses. Thus, the effective response rate is $13.86 \%$. The responding firms span a wide range of industries; most are manufacturing firms (63\%), mostly in the electronics $(14.1 \%)$, computers and communications (12.6\%), and non-metallic production (12.6\%) sectors. Our sample firms vary in total assets and number of full-time employees; approximately half of them own total assets of around US\$60 million and, on average, employ about 500 full-time employees.

We test our model and hypotheses using partial least squares (PLS), which allows for simultaneous testing of both the measurement and structural models [39]. We evaluate our instrument in terms of reliability and convergent and discriminant validity. To evaluate item reliability, we examine the loading of each item on its corresponding construct. Items with a loading greater than .7 are generally reliable, whereas those with a loading lower than .5 should be considered for removal, and all loadings for items are exceed this suggested cutoff threshold [40]. The loadings of all the remaining items are statistically significant at the .01 level.

We analyze our instrument's construct reliability in terms of internal consistency and composite construct reliability. We use Cronbach's alpha to assess internal consistency and adopt the common threshold of .7 [40]. All investigated constructs exhibit a Cronbach's alpha value greater than .7 and thus satisfactory internal consistency. The composite reliability of each construct we investigate exceeds .7, a common threshold in social science research for signifying satisfactory construct reliability [41]. Our overall results thus suggest the instrument's satisfactory construct reliability.

We next examine convergent validity using average variance extracted (AVE) Each investigated construct has an AVE score greater than .6, which indicates our instrument exhibits adequate convergent validity [41]. We further analyze convergent and discriminant validity by examining the cross-loadings computed from the correlation between each construct's component score and the manifest indicators of other constructs [39]. All items load substantially on their own construct compared with any other constructs. The square roots of the AVEs are also greater than the correlation among any pair of latent constructs [39]. Together, these results suggest that the instrument exhibits appropriate convergent and discriminant validity.

Model and Hypothesis Testing Results: We test our model by examining the $\mathrm{R}^{2}$ value of each exogenous variable. As we show in Figure 2, the model explains a significant portion of the variances in dynamic marketing capabilities $\left(\mathrm{R}^{2}=\right.$ $63 \%)$ and IT support for CRM $\left(\mathrm{R}^{2}=42 \%\right)$. We test each hypothesis by assessing the statistical significance and magnitude of its corresponding path in the model. For increased statistical rigor and validity [39], we also use a bootstrap resampling procedure with resamples of 250 . According to our results, market orientation has a significant, direct effect on IT support for CRM (path coefficient $=.53, p<.01$ ). Moreover, IT support for CRM is significantly influenced by the connectivity of IT infrastructure capabilities (path coefficient $=.21, p<.01$ ) but is not significantly affected by the functionality. Thus, our data support $\mathrm{H} 1$ and $\mathrm{H} 3$ but not H5, suggesting the importance of the connectivity, but not the functionality, of a firm's IT infrastructure for the firm's use of IT to support CRM. In addition, market orientation has a significant influence on dynamic marketing capabilities (path coefficient $=.44, p<.01$ ), as does IT support for CRM (path coefficient $=.38, p<.01$ ), in support of H2 and H7. Finally, the effect of the functionality of IT infrastructure capabilities on dynamic marketing capabilities is significant (path coefficient $=.10, p$ $<.01$ ), but connectivity is not; thus, our data support H6 but not H4.

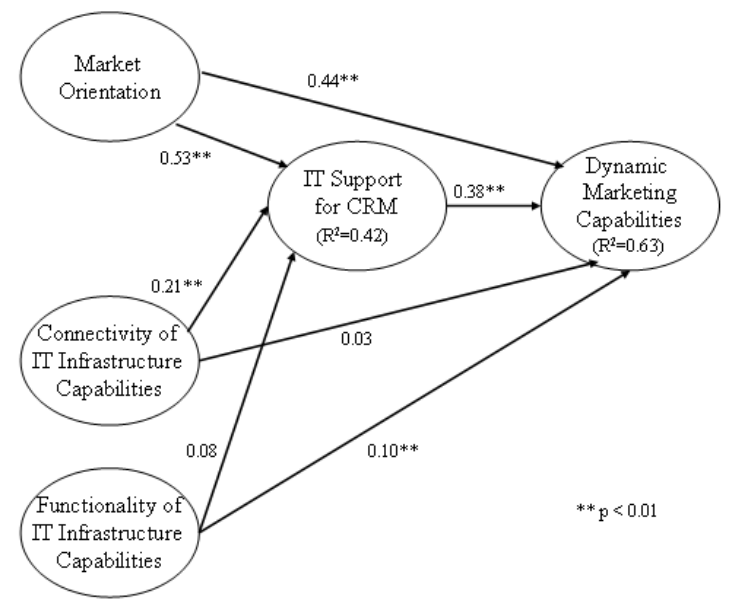

\section{Figure 2: Model Testing Results}

\section{Discussion and Conclusion}

Dynamic capabilities offer a salient anchor for competitive advantage analysis. Whereas most previous research examines dynamic capabilities in a general sense, few studies consider dynamic capabilities from the perspective of critical business aspects of the firm (e.g., marketing). We

\footnotetext{
${ }^{4}$ Detailed data analysis results are available upon request.
} 
study firms' dynamic marketing capabilities by focusing on the central role of IT in supporting CRM and find empirical support for most of the proposed hypotheses. Thus, our model offers reasonably satisfactory utilities for explaining and predicting firms' dynamic marketing capabilities and the effects of IT in creating such capabilities. According to our results, market orientation and IT infrastructure capabilities can affect dynamic marketing capabilities directly as well as indirectly (through IT support for CRM). Our findings also shed light on the important linkage between the use of IT to support CRM and dynamic marketing capabilities. Our study further represents a point of departure for continued investigations of firms' dynamic capabilities at a finer-grained level, specific to critical aspects of business, which should encourage fruitful lines of inquiry into dynamic capabilities.

By examining the central role of IT in creating and enhancing dynamic marketing capabilities, our study contribute to the IS literature by addressing how different types of IT resources can used to create and enhance business values. Our results underscore the criticality of information technology as a means to support CRM and thereby improve dynamic marketing capabilities. Overall, our findings shed light on the importance of IT in dynamic capabilities, which deserves further investigation. According to our analysis, firms that vary in their market orientation also differ in their use of technology to support CRM and in their dynamic marketing capabilities; additional research should explore desirable contingencies that may determine the relative significance of a firm's IT infrastructure capabilities or guide its use of technology to support CRM. Our research also contributes to competitive advantages literature by investigating firms' dynamic marketing capabilities, an essential pre-descriptive measure that indicates a firm's competence in turbulent markets, whereas most prior studies focus on firm performance or examine dynamic capabilities holistically. Prior research tends to study firm performance using static assessments that simply provide snapshots of the firm's performance or operations. The distinction between static and dynamic resources or abilities represents an extension of the traditional static RBV conceptualization [12]. Conceptual analyses and empirical investigations become necessary to explain firms' competitive advantages in highly volatile markets and address key challenges that result from market volatility and fast changing technologies.

Our study results have several implications for research. First, the connectivity and functionality of a firm's IT infrastructure have dissimilar effects on its use of IT to support CRM and on dynamic marketing capabilities. Whereas previous research examines the effects of IT infrastructure as a collective construct, we identify two important dimensions of IT infrastructure according to their distinct definitions and implications and then examine their effects separately. Because functionality represents the ability to provide comprehensive fundamental IT services, whereas connectivity refers to the level of linkages between work groups and applications, these two dimensions provide support for CRM and the cultivation of dynamic marketing capability in different ways. According to our results, functionality influences dynamic marketing capabilities directly, and connectivity affects such capabilities indirectly through the use of IT in support of CRM. Our findings point to the need to examine their separate effects when studying the impact of IT infrastructure on firms or their performance.

Second, our analyses shed light on the mediating role of IT support for CRM, which partially mediates the influence of market orientation on dynamic marketing capabilities. In addition to its direct effect, IT in support of CRM can enhance a firm's dynamic marketing capabilities by mediating the impacts of its market orientation. Similarly, IT support for CRM channels the impact of IT connectivity on dynamic marketing capabilities. According to our results, a firm's use of IT to support its CRM depends on its IT infrastructure, which provides a tangible, foundational architecture of the firm [4]. Taken together, our findings reveal the central role of the use of IT in support of CRM to channel the influences of these antecedents toward dynamic marketing capabilities, thus highlighting a facilitating role that deserves further attention.

Third, our findings underscore the importance of IT for creating or enhancing firms' dynamic marketing capabilities. The use of IT offers a vital linkage between the firm's technology and its business strategy to create competitive advantages. Dynamic marketing capabilities are created by a firm not only to use specific technological capabilities but also to leverage IT in the context of the firm's organizational capabilities [16]. Overall, our results reinforce the alignment between technology investment/utilization and business strategy [16] and vividly underscore the central role of IT in strategic management research, particularly for firms competing in highly volatile markets.

Our findings also have several implications for practice. Though the connectivity of IT infrastructure does not seem to contribute to the 
firm's dynamic marketing capabilities directly, the effects of its connectivity on IT support for CRM cannot be ignored. A firm's technology usage appears most valuable when it is congruent with the firm's business strategies, as illuminated by the use of IT to support CRM. In this light, firms must thoroughly plan their IT investments and carefully assess their assimilation with essential business processes or activities. A firm may not benefit fully from its network upgrades throughout the organization if it fails to use it to support key business processes, such as communications among various functional departments or with customers and suppliers. Alternatively, a firm might improve its collaborative CRM by using a newly implemented communication system (e.g., a VoIP system) that enhances the customer experience and improves coordination among different departments. The functionality of IT infrastructure instead affects dynamic marketing capability directly, which implies that it is important for firms to establish a modular IT infrastructure so that the IT resources can be easily reconfigured to enhance the dynamic marketing capability. However, the functionality of IT infrastructure is not established for a specific application but provides a foundation for shared IT services used by multiple IT applications [23]. Therefore, the effect of functionality does not affect IT-supported CRM significantly.

Our results further point to the essential role of IT support for CRM in market-oriented firms that must maintain a good understanding of their customers and competitors. Accordingly, market-oriented firms are relatively more motivated to exploit technological opportunities to support their CRM. CRM technologies can help the firm achieve its marketing goals, and as our findings show, its market orientation can affect the firm's use of IT to support its dynamic marketing capabilities. That is, market orientation drives customer-centric technology usage, which influences dynamic marketing capabilities. These results reinforce the importance of a desirable fit between the firm's technology usage and key business practices, particularly for market-oriented firms in competitive and volatile markets. Firms should pursue technologies congruent with their core business processes to improve their dynamic marketing capabilities.

This study has several limitations that must be considered when interpreting our results. First, our results derive from a single study involving a sample of firms; therefore, we cannot rule out self-selection biases. Second, measuring IT infrastructure capabilities and dynamic marketing capabilities is challenging. We believe our measures are reasonable, but our study also could benefit from further conceptual analyses and empirical testing. Third, our analysis focuses on some key determinants of dynamic marketing capabilities but may ignore other important antecedents. Additional investigations should consider and test a broader set of factors that may explain how firms create and augment their dynamic marketing capabilities. In addition, dynamic capabilities may straddle multiple dimensions of business, so research should examine other fundamental aspects of firms, such as operations, services, finance, or knowledge management. The role of IT in firms' dynamic capabilities, specific to such dimensions, may differ. Along similar lines, a remaining challenge facing researchers and business managers is identifying the specific aspects of business that firms must develop to improve their dynamic capabilities.

\section{References}

[1] Eisenhardt, K.M. and Martin J.A. "Dynamic Capabilities: What Are They?” Strategic Management. Journal, 21(10-11), 2000), pp.1105-1121.

[2] Teece, D.J., Pisano, G., and Shuen, A. "Dynamic Capabilities and Strategic Management," Strategic Management. Journal, 18(7), 1997, pp.509-533.

[3] Mathiassen, L. and Vainio, A.M. "Dynamic Capabilities in Small Software Firms: A Sense-And-Respond Approach," IEEE Transactions on Engineering Management, 54(3), 2007, pp.522-538.

[4] Ross, J.W., Weill, P., and Robertson, D.C. Enterprise Architecture as Strategy. Boston: Harvard Business School Press, 2006.

[5] Karimi, J., Somers, T.M., and Gupta, Y. "Impact Of Information Technology Management Practices on Customer Service,” Journal of Management Information Systems, 17(4), 2001, pp.125-158.

[6] Sambamurthy, V., Bharadwaj, A., and Grover, V. "Shaping Agility through Digital Options: Reconceptualizing the Role of Information Technology in Contemporary Firms,” MIS Quarterly, 27(2), 2003, pp.237-263.

[7] Dutta, S., Zbaracki, M.J., and Bergen, M. "Pricing Process as A Capability: A Resource-Based Perspective,” Strategic Management Journal, 24(7), 2003, pp.615-630.

[8] Baker, W.E. and Sinkula, J.M. "The Synergistic Effect of Market Orientation and Learning Orientation on Organizational Performance,” Academy of Marketing 
Science Journal, 27(4), 1999, pp.411-428.

[9] Jaworski, B.J. and Kohli, A.K. "Market Orientation: Antecedents and Consequences,” Journal of Marketing, 57(3), 1993, pp.53-70.

[10] Slater, S.F. and Narver, J.C. "Does Competitive Environment Moderate the Market Orientation Performance Relationship?” Journal of Marketing, 58(1), 1994, pp.46-55.

[11] Bhattacharya, C.B. and Sen, S. "ConsumerCompany Identification: A Framework for Understanding Consumers' Relationships with Companies," Journal of Marketing, 67(2), 2003, pp.76-88.

[12] Wade, M. and Hulland, J. “The ResourceBased View and Information Systems Research: Review, Extension, and Suggestions for Future Research,” MIS Quarterly, 28(1), 2004, pp.107-142.

[13] Barney, J. "Firm Resources and Sustained Competitive Advantage," Journal of Management, 17(1), 1991, pp.99-120.

[14] Zollo, M. and Winter, S.G. "Deliberate Learning and the Evolution of Dynamic Capabilities,” Organization Science, 13(3), 2002, pp.339-351.

[15] Bierly, P.E. III, and Chakrabarti, A.K. "Technological Learning, Strategic Flexibility, and New Product Development in the Pharmaceutical Industry," IEEE Transactions on Engineering Management, 43(4), 1996, pp.368-380.

[16] Iyer, G., Ravindran, S., and Reckers, P.M.J. "Procurement of IT Consulting Services and Firm-Specific Characteristics," Journal of the Association for Information Systems, 7(4), 2007, pp.207-239.

[17] Pavlou, P.A. and El Sawy O.A. "From IT Leveraging Competence to Competitive Advantage in Turbulent Environments: The Case of New Product Development," Information Systems Research, 17(3), 2006, pp.198-227.

[18] Winter. S.G. "Understanding Dynamic Capabilities,” Strategic Management Journal, 24(10), 2003, pp.991-995.

[19] Kohli, A.K. and Jaworski, B.J. "Market Orientation: The Construct, Research Propositions and Managerial Implications,” Journal of Marketing, 54(2), 1990, pp.1-18.

[20] Kohli, A.K., Jaworski, B.J., and Kumar, A. "MARKOR: A Measure of Market Orientation,” Journal of Marketing Research, 30(4), 1993, pp.467-477.

[21] Siguaw, J.A., Simpson, P.M., and Baker, T.L. "Effects of Supplier Market Orientation on Distributor Market Orientation and the
Channel Relationship: The Distributor Perspective,” Journal of Marketing, 62(3), 1998, pp.99-111.

[22] Broadbent, M., Weill, P., and Neo, B.S. "Strategic Context and Patterns of IT Infrastructure Capability," Journal of Strategic Information Systems, 8(2), 1999, pp.157-187.

[23] Keen, P.G.W. Shaping the Future: Business Design through Information Technology. Boston: Harvard Business School Press, 1991.

[24] Niraj, R., Gupta, M., and Narasimhan, C. "Customer Profitability in a Supply Chain," Journal of Marketing, 65(3), 2001, pp.1-16.

[25] Hurley, R.F. and Hult, G.T.M. "Innovation, Market Orientation, and Organizational Learning: An Integration and Empirical Examination,” Journal of Marketing, 62(3), 1998, pp.42-54.

[26] Kirca, A.H., Jayachandran, S., and Bearden, W.O. "Market Orientation: A Meta-Analytic Review and Assessment of Its Antecedents and Impact on Performance," Journal of Marketing, 69(2), 2005, pp.24-41.

[27] Narver, J.C. and Slater, S.F. “The Effect of a Market Orientation on Business Profitability," Journal of Marketing, 54(4), 1990, pp.20-35.

[28] Png, I.P.L., Tan, B.C.Y. and Wee, K.-L. "Dimensions of National Culture and Corporate Adoption of IT Infrastructure,” IEEE Transactions on Engineering Management, 48(1), 2001, pp.36-45.

[29] Fink, L. and Neumann, S. "Gaining Agility through IT Personnel Capabilities: The Mediating Role of IT Infrastructure Capabilities," Journal of the Association for Information Systems, 8(8), 2007, pp.440-462.

[30] Duncan, N.B. "Capturing Flexibility of Information Technology Infrastructure: A Study of Resource Characteristics and Their Measure,” Journal of Management Information Systems, 12(2), 1995, pp.37-57.

[31] Byrd, T.A. and Turner, D.E. "An Exploratory Analysis of the Value of the Skills of IT Personnel: Their Relationship to IS Infrastructure and Competitive Advantage,” Decision Science, 32(1), 2001, 21-54.

[32] Jayachandran, S., Sharma, S., Kaufman, P. and Raman, P. "The Role of Relational Information Processes and Technology Use in Customer Relationship Management," Journal of Marketing, 69(4), 2005, pp.177-92.

[33] Srivastava, R.K., Shervani, T.A., and Fahey, 
L. "Marketing, Business Processes and Shareholder Value: An Organizationally Embedded View of Marketing Activities and the Discipline of Marketing," Journal of Marketing, 63, 1999, 168-179.

[34] Boulding, W., Staelin, R., Ehret, M., and Johnston, W.A. "Customer Relationship Management Roadmap: What Is Known, Potential Pitfalls, and Where to Go," Journal of Marketing, 69(4), 2005, pp.155-166.

[35] Swift, R.S. Accelerating Customer Relationships: Using CRM and Relationship Technologies. Upper Saddle River, NJ: Prentice Hall PTR, 2000.

[36] Day, G.S. "The Capabilities of MarketDriven Organizations," Journal of Marketing, 58(4), 1994, pp.37-52.

[37] Brancheau, J.C., Janz, B.D., and Wetherbe,
J.C. "Key Issues in Information Systems Management: 1994-95 SIM Delphi Results,” MIS Quarterly, 20(2), 1996, pp.225-242.

[38] Quinn, J.B. Intelligent Enterprise: A Knowledge and Service Based Paradigm for Industry. New York: The Free Press, 1992.

[39] Chin, W.W., "The Partial Least Squares Approach for Structural Equation Modeling," In: G.A. Marcoulides (ed.), Modern Methods for Business Research. Mahwah, NJ: Lawrence Erlbaum Associates, 1998, pp.295-336.

[40] Nunnally, J. Psychometric Theory. New York: McGraw-Hill, 1978.

[41] Fornell, C. and Larcker, D.F. "Evaluating Structural Equation Models with Unobservable Variables and Measurement Error,” Journal of Marketing Research, 18(1), 1981, pp.39-50. 